\title{
Systematic and comprehensive investigation of the toxicity of curcuminoid-essential oil complex: A bioavailable turmeric formulation
}

\author{
MADAN L. AGGARWAL ${ }^{1}$, KARAMPENDETHU M. CHACKO $^{1}$ and BINU T. KURUVILLA ${ }^{2}$ \\ ${ }^{1}$ Shriram Toxicology Centre, Shriram Institute for Industrial Research, Delhi 110007; \\ ${ }^{2}$ Research and Development Laboratory, Arjuna Natural Extracts Ltd., Keezhmad, Kerala 683112, India
}

Received December 20, 2014; Accepted September 22, 2015

DOI: $10.3892 / \mathrm{mmr} .2015 .4579$

\begin{abstract}
Curcumin, the active component present in Curcuma longa of the family Zingiberaceae, has a number of pharmacological effects, including potential anti-inflammatory activity. One of the major limitations of curcumin/turmeric extract is its poor absorption through the gastrointestinal tract. Several approaches have been adopted to increase the bioavailability of curcumin, including loading curcumin into liposomes or nanoparticles, complexation with phospholipids, addition of essential oils and synthesizing structural analogues of curcumin. In the present study, the toxicity and safety of one such bioavailable turmeric formulation, curcuminoid-essential oil complex (CEC), the toxicity profile of which has not been reported, were examined using in vivo and in vitro models, as per the guidelines of the Organisation for Economic Co-operation and Development. Investigations of acute toxicity study were performed in rats and mice, and the results revealed no signs and symptoms or toxicity or mortality in any of the animals at the maximum recommended dose level of $5,000 \mathrm{mg} / \mathrm{kg}$ body weight. The repeated administration of CEC for 90 days in Wistar rats at a dose of $1,000 \mathrm{mg} / \mathrm{kg}$ body weight did not induce any observable toxic effects, compared with corresponding control animals. Mutagenicity/genotoxicity investigations were also performed using a bacterial reverse mutation assay (Ames test), a mammalian bone marrow chromosome aberration test and a mammalian erythrocyte micronucleus test in mice. CEC was found to be non-mutagenic in all three mutagenic investigations. Consequently, the present study indicated that CEC elicited no toxic effects in animals or in vitro. Therefore, following investigations of acute toxicity,
\end{abstract}

Correspondence to: Dr Binu T. Kuruvilla, Research and Development Laboratory, Arjuna Natural Extracts Ltd., Nalam Mile Kulakadu Road, Erumathala, Keezhmad, Kerala 683112, India E-mail: binutkuruvilla@gmail.com

Key words: ames test, curcumin, Curcuma longa, mammalian bone marrow chromosome aberration test, mutagenicity studies, toxicity repeated dose toxicity and mutagenicity, CEC was deemed a safe, non-toxic pharmacological formulation.

\section{Introduction}

Curcuma longa Linn. of the family Zingiberaceae, is a perennial herb, which measures up to $1 \mathrm{~m}$ high with a short stem. The powdered rhizome, turmeric, has been in continuous use for its flavoring and digestive properties. Turmeric is used extensively in India and other South Asian cuisines, and is a significant ingredient in the majority of curry powders. It is also used as a home remedy for cuts and burns, and is an integral part of the religious traditions and customs of the Hindu religion (1). For thousands of years, turmeric has been used in Ayurveda for a wide range of disorders, including biliary disorders, anorexia, coryza, cough, wounds, hepatic disorders, rheumatic disorders, sprains and swellings caused by injury, and sinusitis (2). The volatile oil obtained from $C$. longa also exhibits potent anti-inflammatory and anti-arthritic activities (3).

The major constituent of turmeric rhizomes is a yellow-colored phenolic pigment, known as curcumin. In the crude extract of rhizomes of $C$. longa, $\sim 75-80 \%$ curcumin is present, along with $\sim 15-20 \%$ demethoxycurcumin and $3-5 \%$ bisdemethoxycurcumin (4).

Curcumin is capable of modulating the activities of a range of transcription factors and signaling pathways, which are important in several diseases, and include nuclear factor- $\kappa \mathrm{B}$, activator protein-1, Janus kinase/signal transducer and activator of transcription, Akt, B cell lymphoma-2, caspases, poly ADP ribose polymerase, I $\mathrm{B}$ kinase, epidermal growth factor receptor, platelet-derived growth factor, human epidermal growth factor receptor 2, nuclear factor erythroid 2 -related factor 2, $\beta$-catenin/ T-cell factor, c-Jun N-terminal kinase, mitogen-activated protein kinase, cyclooxygenase and 5-lipoxygenase (5). It also inhibits the undesirable activities of a number of cytokines, including tumor necrosis factor- $\alpha$ and interleukins, which are pivotal in inflammation. Its high antioxidant potential and metal chelating properties further widen its range of activities (6,7). Thus, curcumin can act on multiple targets and at multiple levels, and offer substantial benefits in a number of diseases, including cancer, heart 
disease, diabetes, rheumatoid arthritis, Alzheimer's disease, inflammatory bowel diseases, liver fibrosis and cirrhosis, HIV, pancreatitis, drug-resistant malaria (8-10). It is reported to be a safe chemopreventive agent and one the few molecules capable of preventing cancer metastasis (11).

Curcumin has a poor solubility in water, with the maximum solubility reported to be $11 \mathrm{ng} / \mathrm{ml}$ in aqueous buffer ( $\mathrm{pH}$ 5.0) (12). The oral bioavailability of curcumin is low, at only $1 \%$ in rats, and higher doses are required to achieve significant pharmacological effects (13). In previous clinical trials, quantifiable serum levels were not achieved until doses of up to $3.6 \mathrm{~g}$ were used $(14,15)$. To improve the oral bioavailability of curcumin, several approaches have been investigated. These approaches include loading curcumin into liposomes or nanoparticles, forming self-microemulsifying drug delivery systems, complexation with phospholipids, addition of essential oils and synthesizing structural analogues of curcumin (16-18).

Turmeric extracts and curcumin have been investigated for their toxicity in several studies and have been found to be safe $(19,20)$. Bioavailability investigations with these regular extracts have shown low serum levels of curcumin following oral administration in animals $(21,22)$. Due to poor oral absorption, high doses of turmeric extract are required to achieve significant pharmacological effects, however, high doses may induce significant toxicity (23). The emergence of extracts claiming bioavailable curcumin has led to debate over the presence of several higher fold levels of curcumin in the blood and tissues and its safety. In addition, the external bioenhancing agents added pose additional safety concerns. Although higher bioavailability leads to the improved delivery of therapeutic levels of curcumin in vivo, the detailed safety profile of curcumin, as well as the added bioenhancers, require evaluation. In the present study the toxicity and safety of one such bioavailable turmeric formulation, curcuminoid-essential oil complex (CEC), was investigated in in vitro and in vivo animal models, as the toxicity profile has not been reported previously.

CEC differs from regular turmeric extracts, as it contains curcuminoids and essential oil of turmeric containing turmerones in a specific ratio. CEC has been characterized previously using ultra performance liquid chromatography and gas chromatography-mass spectrometry methods (24).

Another important reason to assess the toxicity and safety of curcumin is its wide use as a coloring agent in food and beverages. The permissible levels of curcumin as a food colorant in the EU is between 20 and $500 \mathrm{mg} / \mathrm{kg}$, and in beverages is up to $200 \mathrm{mg} / \mathrm{l}$. As turmeric is widely used in cooking, exposure assessment also requires consideration of dietary exposure to curcumin. The estimated combined exposure to curcumin from naturally occurring curcumin in foods and from its use as a food color, ranges between 1.6 and $7.6 \mathrm{mg} / \mathrm{kg}$ body weight (bw)/day for children and $2.6 \mathrm{mg} / \mathrm{kg}$ bw/day for adults (25). Curcumin was evaluated by the Joint Food and Agriculture Organization of the United Nations and the World Health Organization Expert Committee on Food Additives in 2004 and established an allocated daily intake (ADI) of $0-3 \mathrm{mg} / \mathrm{kg}$ bw/day (26). However, this does not take into account the combined dietary exposure of curcumin. European Food Safety Authority panel noted that the maximum levels of exposure to curcumin in children are above the ADI of $3 \mathrm{mg} / \mathrm{kg}$ bw/day in certain European countries (25).

Curcumin is currently widely used as a nutraceutical product for various indications. The recommended dosage of curcumin extracts for the general population ranges between 500 and $1,500 \mathrm{mg} /$ day (27), which is higher than the recommended ADI of $3 \mathrm{mg} / \mathrm{kg}$ bw/day.

$\mathrm{CEC}$ is one of the commercial curcumin formulations claimed to have higher levels of bioavailability. The turmerone rich essential oil of turmeric present in CEC enhances the bioavailability of curcumin when administered orally. In a pilot crossover investigation in humans, the relative bioavailability of CEC was $~ 6.93$-fold higher, compared with normal curcumin, and $\sim 6.3$-fold higher, compared with curcumin-lecithin-piperine formula (28). Previous reports on the toxicity of regular turmeric extracts or curcumin cannot be associated with the bioavailable CEC. Therefore, evaluation of the toxicity of higher curcumin levels in vivo from CEC is important to confirm its safety for human use. The aim of the present study was to evaluate the toxicity and safety of CEC in a well established animal models, including the assessment of acute toxicity in mice and rats, sub-chronic toxicity in rats and mutagenicity assessment.

\section{Materials and methods}

Drugs and reagents. 2-nitro fluorine, sodium azide, mitomycin C, 9-aminoacridine, 2-amino anthracene, cyclophosphamide and colchicine were purchased from Sigma-Aldrich (St. Louis, MO, USA). Potassium chloride was purchased from Loba Chemie PVT., Ltd. (Mumbai, India). Salmonella typhimurium culture discs (Moltox) were obtained from Krishgen Biosystems (Whittier, CA, USA). Standard laboratory rat feed was purchased from Pranav Agro Industries, Ltd. (Banagalore, India). CEC (containing 95\% curcuminoid complex) was provided by Arjuna Natural Extracts Ltd. (Aluva, India).

Animals. Wistar albino rats, weighing 160-200 g, and Swiss albino mice, weighing 20-25 g, were used for toxicity and mutagenicity investigations. The room temperature was maintained at $22 \pm 3^{\circ} \mathrm{C}$ with $30-70 \%$ relative humidity. The room was ventilated at a rate of $\sim 15$ air changes/h. Lighting was controlled to provide $12 \mathrm{~h}$ artificial light ( $8 \mathrm{am}-8 \mathrm{pm})$ each day. Filtered water and sterilized standard pelleted feed (Pranav Agro Industries Ltd.) was available ad libitum to the experimental animals. All experimental protocols were approved by the Institutional Animal Ethics Committee of Shriram Institute for Industrial Research (Delhi, India), and guidelines set by the Committee for the Purpose of Control and Supervision of Experiments on Animals (http://icmr.nic. in/bioethics/final_cpcsea.pdf) were adhered to.

Acute toxicity evaluation in mice. A total of 20 Swiss albino mice (10 males/10 females), weighing 20-25 g and aged 8-12 weeks, were used for the evaluation of acute toxicity. The investigation was divided into two steps, as per the guidelines of the Organization for Economic Cooperation and Development (OECD; no. 420) (29). The animals were acclimatized for 5 and 7 days for steps I and II, respectively, prior to commencement of each step. The animals were fasted 
$4 \mathrm{~h}$ prior to, and $2 \mathrm{~h}$ following, treatment. In the first step, one female and one male mouse were used to perform a limit test. The test substance (CEC dissolved in corn oil; $200 \mathrm{mg} / \mathrm{ml}$ w/v) was administered orally at a dose of $5,000 \mathrm{mg} / \mathrm{kg}$ bw $(2.5 \mathrm{ml} / 100 \mathrm{~g} \mathrm{bw})$, via a cannula attached to a syringe. No mortality, or signs and symptoms of toxicity were observed in any animals, therefore, to confirm these findings, the second step was performed by assessing four female and male mice, which were administered the same dose of $5,000 \mathrm{mg} / \mathrm{kg}$ bw.

Similarly, a group of five male and female mice were treated with vehicle (corn oil), in a stepwise manner, and were designated as the control group, comprising one female and male mouse in the first step, and four female and male mice in the second step. The animals were observed for a total period of 14 days. No mortality or treatment-associated signs or symptoms of toxicity were observed in the animals in either of the steps. As a result of these findings, no further assessment was required. After 14 days, the animals were sacrificed using $\mathrm{CO}_{2}$ asphyxiation. Gross pathological changes, if any, were recorded.

Acute toxicity assessment in rats. As it is recommended that acute toxicity is evaluated in two mammalian species prior to initial human exposure, according to the FDA Single Dose Acute Toxicity Testing for Pharmaceuticals; Revised Guidance (61 FR43934 to 43935; August 26, 1996), CEC was also investigated in rats. A total of 20 Wistar albino rats $(10$ males and 10 females) weighing 160-200 g, aged 8-12 weeks, were used for this assessment. The investigation was divided into two steps, as per OECD guidelines (no. 420) (29). The animals were acclimatized for 5 and 7 days for steps I and II, respectively, prior to commencement of each step. The animals were fasted overnight prior to, and $4 \mathrm{~h}$ following, treatment. In the first step, one female and one male rat were assessed using a limit test. The test substance (CEC dissolved in corn oil) was administered orally at a dose of $5,000 \mathrm{mg} / \mathrm{kg}$ bw using a cannula attached to a syringe. No mortality, or signs and symptoms of toxicity were observed in any animals. Therefore, to confirm these findings, the second step was performed using four more female and male rats, which were administered with the same dose of $5,000 \mathrm{mg} / \mathrm{kg}$ bw.

Similarly, a group of five male and female rats were treated with vehicle (corn oil), in a stepwise manner, and were designated as the control group (one female and male rat in the first step; four female and male rats in the second step). The animals were observed for a total period of 14 days. No mortality or treatment associated signs and symptoms of toxicity were observed in the animals in either step. As a result, no further assessment was required. After 14 days, the animals were sacrificed using $\mathrm{CO}_{2}$ asphyxiation. Gross pathological changes, if any, were recorded.

Assessment of 90-day repeated dose oral toxicity in rats. The assessment of repeated dose was performed as per OECD guidelines for Testing of Chemicals (no. 408). A total of 100 Wistar albino rats (50 males and 50 females) were divided into four groups of 20 animals, each comprising 10 males and 10 females, and satellite groups of 10 animals (five males and five females). The animals were acclimatized for 7 days prior to commencement of treatment. Subsequently, three of the groups of 20 rats were administered with CEC orally at a dose of $100 \mathrm{mg} / \mathrm{kg}$ bw (low dose), $500 \mathrm{mg} / \mathrm{kg}$ bw (intermediate dose) and 1,000 mg/kg bw (high dose), respectively, each day for 90 days, using a cannula attached to a syringe. The fourth group of 20 rats were orally administered with corn oil only (vehicle) for 90 days and was designated the control group.

The two satellite groups of 10 rats were designated the satellite control and satellite high dose groups, and were administered with corn oil (vehicle) and CEC (1,000 mg/kg), respectively, for 90 days. Homogeneity of the test sample was maintained on a magnetic stirrer during administration. Following sacrifice of the experimental and control groups of animals, the satellite control and satellite high dose groups were maintained under observation for an additional 28 days to assess for reversibility, persistence or delayed toxic effects, if any. The animals were observed daily for behavior, appearance and toxicological signs and symptoms. The animals were anaesthetized using anaesthetic ether stabilized with $0.002 \%$ propyl gallate (Sharad Laboratories, Andhra Pradesh, India) and $2 \mathrm{ml}$ Blood was collected from the retro-orbital sinus under light anesthesia from all animals prior to sacrifice for detailed hematological and biochemical evaluation. Urine samples ( $24 \mathrm{~h}$ samples of $\sim 6-8 \mathrm{ml}$ ) were also collected from all animals at the termination of the experiment, and were analyzed for appearance/colour, specific gravity, $\mathrm{pH}$, glucose, proteins, ketones, bilirubin, urobilinogen, nitrite and white blood cells. Additionally, $3 \mathrm{ml}$ of the urine samples were centrifuged at 2,000 rpm for $5 \mathrm{~min}$, and sediments were examined for pus cells, epithelial cells, casts, red blood cells and crystals. Criteria used to evaluate compound-associated effects included appearance, behavior, morbidity and mortality rates, body weights, feed consumption, hematological and biochemical analysis, urine analysis, organ weights, necropsy and histopathology. All these assessments and analyses were performed at Shriram Toxicology Centre, Shriram Institute for Industrial Research (Delhi, India).

Mutagenicity assessment. A bacterial reverse mutation assay (Ames test) was performed, in which CEC was assessed against five strains of Salmonella typhimurium viz. (TA-98, TA-100, TA-102, TA-1535 and TA-1537), with and without metabolic activation (S-9 liver fraction; Krishgen Biosystems, Whittier, CA, USA), at concentrations of 1,000, 2,000, 3,000, 4,000 and 5,000 $\mu \mathrm{g} /$ plate. The experiment was performed as per OECD guidelines (no. 471). For the mutation assessment, sub culture was prepared in nutrient broth and grown overnight at $37^{\circ} \mathrm{C}$ in an incubator. The overnight culture provided $\sim 1 \times 10^{9}$ cells $/ \mathrm{ml}$. The actual number of cells was assessed by cell counting and was used as the standard bacterial suspension.

The solvent, dimethyl sulfoxide (DMSO; 5,000 $\mu \mathrm{g} / \mathrm{plate}$ ), was included as a negative control in the same bacterial cultures, and S-9 mix (10\% solution in $\mathrm{pH} 7.4 \mathrm{PBS}$ ) was used as the test substance $(0.5 \mathrm{ml} /$ plate $)$. The quantity of DMSO was equal to the maximum quantity used in the plates. To ensure strain integrity and effectiveness of the metabolic activation system, positive control compounds were included in each assay, with and without the metabolic activation system. 2-nitro fluorine (10 $\mu \mathrm{g} /$ plate), sodium azide (5 $\mu \mathrm{g} / \mathrm{plate})$, mitomycin C (2.5 $\mu \mathrm{g} /$ plate), 9-aminoacridine (20 $\mu \mathrm{g} /$ plate), 
and 2-amino anthracene ( $2 \mu \mathrm{g} / \mathrm{plate})$ dissolved in DMSO were used as positive controls.

Following incubation at $37^{\circ} \mathrm{C}$ in the dark for $48 \mathrm{~h}$, the petri dishes were observed under a microscope (Olympus BX46; Olympus Corporation, Tokyo Japan) for the growth of revertant bacterial colonies at all five concentrations $(1,000,2,000$, $3,000,4,000$ and 5,000 $\mu \mathrm{g} /$ plate), as well as in the negative control and positive controls against all the bacterial strains assessed, with and without metabolic activation.

\section{Mammalian bone marrow chromosome aberration test in} rats. A total of 60 albino wistar rats (30 males and 30 females; $\sim 8-12$ weeks old) were selected and randomly distributed into three groups of 10 females and males. The animals were acclimatized for 5 days prior to commencement of treatment.

The first group of 20 wistar rats (10 males and 10 females) were administered orally with CEC (dissolved in corn oil) at a single dose of $2,000 \mathrm{mg} / \mathrm{kg}$ bw via a cannula attached to a syringe. Similarly, the second group (negative control group) of 20 rats was administered with corn oil (vehicle) only. Cyclophosphamide was administered as a positive control in the third group of 20 rats, at a dose of $50 \mathrm{mg} / \mathrm{kg}$ bw intraperitoneally.

Subsequently, $2 \mathrm{~h}$ prior to sacrifice (16 and $40 \mathrm{~h}$ following treatment with the respective compound), the animals in each group were treated with colchicine at a dose of $4 \mathrm{mg} / \mathrm{kg}$ bw intraperitoneally. Subsequently, five male and five female wistar rats from each group were sacrificed by cervical dislocation at specified time intervals (18 and $42 \mathrm{~h}$ following treatment) and both femora were removed from each animal. The femora were cleared of tissue, and the bone marrow cells were aspirated using Hank's Balanced Salt Solution, followed by centrifugation for $10 \mathrm{~min}$ at $581 \mathrm{x} \mathrm{g}$ at $4^{\circ} \mathrm{C}$. The cells were then treated with hypotonic potassium chloride solution $\left(0.56 \%\right.$ for $30 \mathrm{~min}$ at $\left.37^{\circ} \mathrm{C}\right)$ to cause swelling of the cells. Following further centrifugation for $10 \mathrm{~min}$ at $581 \mathrm{x} \mathrm{g}$ at $4^{\circ} \mathrm{C}$, the cells were fixed in methanol: glacial acetic acid $(3: 1 \mathrm{v} / \mathrm{v})$ and a homogenous cell suspension was prepared. Final cell suspensions were then dropped onto pre-cleaned microscopic slides, which were maintained at $4^{\circ} \mathrm{C}$ prior to use. Two slides were prepared from each animal, and were dried at room temperature, followed by staining with Giemsa (Sigma-Aldrich) and mounting in DPX. The slides were then scored for chromosomal aberration. Standard forms were used to record gaps, breaks and reunion figures, and 100 metaphase spreads with intact diploid chromosomes were scored for each animal. A mitotic index was calculated based on 1,000 cells, which was calculated by scoring the number of cells in mitosis per 1,000 cells observed.

Mammalian erythrocyte micronucleus test in mice. A total of 60 mice (30 males and 30 females; 8-12 weeks old) were selected and randomly distributed into three groups containing 10 males and females. The females used in the present study were nulliparous and non-pregnant. The animals were acclimatized for 5 days prior to commencement of treatment.

The first group of 20 mice was administered with CEC orally at a dose of $2,000 \mathrm{mg} / \mathrm{kg}$ bw (maximum tolerated dose), using a metallic cannula attached to a syringe. The second group of 20 mice was administered orally with corn oil only (negative control). As a positive control group, the third group of 20 mice were treated with cyclophosphamide at a dose of $40 \mathrm{mg} / \mathrm{kg}$ bw intraperitoneally. The animals were sacrificed 24 and $48 \mathrm{~h}$ following treatment by cervical dislocation. At each time point, five male and five female mice from each group were sacrificed. Both femur bones were removed, muscle teased and the ends were carefully shortened using scissors until a small opening to the marrow canal become visible. Subsequently, $2 \mathrm{ml}$ fetal calf serum was injected into the mouth of the marrow cavity using a syringe attached to a needle, and the marrow was flushed into centrifuge tubes. The bone marrow suspension in the fetal calf serum was centrifuged at 1,500 rpm for $10 \mathrm{~min}$, and the supernatant was removed using a Pasteur pipette. The cells in the sediment were carefully mixed and a small drop of this cell suspension was placed on a microscopic slide, from which smear slides were prepared. The smears were fixed in methanol for $15 \mathrm{~min}$ and stained with Giemsa (5\% in deionized water). A total of 200 erythrocytes in the bone marrow cells were scored in each slide, and the total numbers of immature erythrocytes and mature erythrocytes were counted, from which the percentage of immature erythrocytes were recorded. The total number of micronuclei present in the 2,000 immature erythrocytes was also noted.

Statistical Analysis. The data were statistically analyzed using a GraphPad Prism software (version 4; GraphPad Software, Inc., San Diego, CA, USA). Total variation present in a set of data was analyzed using one-way analysis of variance, followed by Dunnet's t-test. $\mathrm{P}<0.05$ was considered to indicate a statistically significant difference. Data are presented in tabular form as the mean \pm standard deviation.

\section{Results}

Acute toxicity in mice. In the acute toxicity assessment performed in the present study, no clinical signs of toxicity were observed in any of the treated or control mice at the dose of $5,000 \mathrm{mg} / \mathrm{kg}$ body weight. Similarly, no mortality was observed in the animals in either step I or step II following administration of corn oil or CEC at $5,000 \mathrm{mg} / \mathrm{kg}$ bw. Individual body weights were recorded prior to oral administration (day 0 ), and on days 7 and 14 following oral administration. The increase in the body weights $(\%)$ of the CEC-treated animals $(5,000 \mathrm{mg} / \mathrm{kg} \mathrm{bw})$ were comparable to the weight gain in the control animals (Fig. 1). The difference in body weights between the control and respective test groups were not statistically significant. All animals were sacrificed via $\mathrm{CO}_{2}$ asphyxiation at the end of the investigation, and no abnormalities of pathological significance were observed. External examination of the sacrificed mice also revealed no abnormality of pathological significance.

No mortality or signs and symptoms of toxicity were observed in any of the animals at the maximum recommended dose of $5,000 \mathrm{mg} / \mathrm{kg}$ bw CEC. Therefore, the maximal tolerance dose (MTD), minimal lethal dose (MLD) and lethal dose, $50 \%$ (LD50) of CEC for mice was $>5,000 \mathrm{mg} / \mathrm{kg}$ bw.

Acute toxicity in rats. No clinical signs of toxicity were observed in any of the CEC-treated or control rats at a dose of 
Table I. Consumption of feed in the 90 day repeated dose toxicity test in rats.

\begin{tabular}{lrr}
\hline & \multicolumn{2}{c}{ Average daily feed consumption $(\mathrm{g})$} \\
\cline { 2 - 3 } Group & \multicolumn{1}{c}{ Male } & Female \\
\hline Control $(\mathrm{n}=10)$ & $181.87 \pm 8.60$ & $183.06 \pm 8.81$ \\
Low dose $(\mathrm{n}=10)$ & $183.46 \pm 7.71$ & $180.52 \pm 7.81$ \\
Intermediate dose $(\mathrm{n}=10)$ & $184.50 \pm 7.22$ & $185.69 \pm 7.10$ \\
High dose $(\mathrm{n}=10)$ & $182.79 \pm 9.08$ & $182.67 \pm 8.29$ \\
Satellite control $(\mathrm{n}=5)$ & $94.24 \pm 3.24$ & $93.60 \pm 4.02$ \\
Satellite high dose $(\mathrm{n}=5)$ & $95.15 \pm 2.64$ & $94.15 \pm 3.25$ \\
\hline
\end{tabular}

Data are presented as the mean \pm standard deviation. Analysis of variance was used for statistical analysis. No significant differences were observed between the test group and their respective control group $(\mathrm{P}>0.05)$.

$5,000 \mathrm{mg} / \mathrm{kg}$ bw. Similarly, no mortality was observed in the animals in step I or step II, following administration with corn oil or CEC at $5,000 \mathrm{mg} / \mathrm{kg}$ bw. Individual body weights were recorded prior to oral administration (day 0), and on days 7 and 14 following oral administration. The increase in body weights $(\%)$ of the treated animals $(5,000 \mathrm{mg} / \mathrm{kg} \mathrm{bw})$ was comparable to the percentage weight gain of control animals (Fig. 2). The differences in body weights between the control and respective test groups, were not statistically significant. All animals were sacrificed via $\mathrm{CO}_{2}$ asphyxiation, at the end of the experiment, at which no abnormalities of pathological significance were observed. External examination of the sacrificed rats also revealed no abnormality of pathological significance.

No mortality of signs and symptoms of toxicity were observed in any of the animals at the maximum recommended dose of $5,000 \mathrm{mg} / \mathrm{kg}$ bw CEC. Therefore, the MTD, MLD and LD50 of the CEC for rats was confirmed as $>5,000 \mathrm{mg} / \mathrm{kg}$ bw.

Toxicity of 90 day-repeated dose in rats. No treatment-associated signs or symptoms of toxicity were observed in the low dose $(100 \mathrm{mg} / \mathrm{kg} \mathrm{bw})$, intermediate dose $(500 \mathrm{mg} / \mathrm{kg} \mathrm{bw})$, high dose $(1,000 \mathrm{mg} / \mathrm{kg}$ bw) or satellite high dose $(1,000 \mathrm{mg} / \mathrm{kg} \mathrm{bw})$ groups of animals, compared with their respective control counterparts. The body weights of all the test and control group animals were recorded weekly. The increase in body weight of the rats in the three treatment groups and satellite high dose group were comparable to those in their respective control counterparts. The consumption of feed by the animals in the low dose, intermediate dose, high dose and satellite high dose groups were comparable to those in the control group and satellite control group animals (Table I).

There were no variations in the hematological parameters of the animals in the low dose, intermediate dose, high dose or satellite high dose groups, compared with their respective control groups (Tables II and III). Similarly, the biochemical parameters of the animals in the low dose, intermediate dose and high dose groups were comparable with the biochemical parameters of their respective control group animals at the point of sacrifice. The biochemical parameters of the satellite high dose group were also comparable to those of the satellite control counterpart (Tables IV and V). Therefore, the hematological and biochemical parameters of the CEC-treated groups were not significantly different from their respective control groups.

Urine samples were collected from all animals at termination of the experiment. No significant changes were noted in the urine parameters of any of the CEC groups, compared with the control groups. The animals in the satellite groups were sacrificed 28 days post-treatment. No animals succumbed to morality during the experiment in any of the CEC-treated groups or satellite groups. Following completion of the 90 day treatment period, the animals in all groups, with the exception of the satellite groups, were sacrificed and were examined for gross pathological features. The organs of all the animals (treatment and control) were trimmed of any adherent fat tissue and their weights were measured. The organ weights of the animals in all treatment groups were comparable to those of their respective control counterparts. No significant histopathological changes were identified in the animals of the low dose group, intermediate dose group, high dose group or satellite high dose group, compared with their control counterparts (Fig. 3).

Therefore, the repeated oral administration of CEC for 90 days to wistar rats at a dose of $1,000 \mathrm{mg} / \mathrm{kg}$ bw did not induce any observable toxic effects, compared with the corresponding control group, and this dose may be considered a 'no observed adverse effect level'.

Ames test. CEC was subsequently assessed against five strains of Salmonella typhimurium viz.(TA-98, TA-100,TA-102, TA-1535 and TA-1537), with and without metabolic activation, at concentrations of 1,000, 2,000, 3,000, 4,000 and 5,000 $\mu \mathrm{g} /$ plate. The test was negative in all strains, with or without metabolic activation (Table VI), as no growth was observed at any of the test concentrations, compared with that in the untreated control. No significant differences were observed in the number of colonies in the CEC groups, compared with the negative control group. However, growth was observed in the positive control group, confirming the sensitivity of the Salmonella typhimurium strains. The numbers of colonies in the positive control groups were significantly different from those in the negative control groups. Therefore, under the conditions of the present study, CEC was found to be non-mutagenic. 


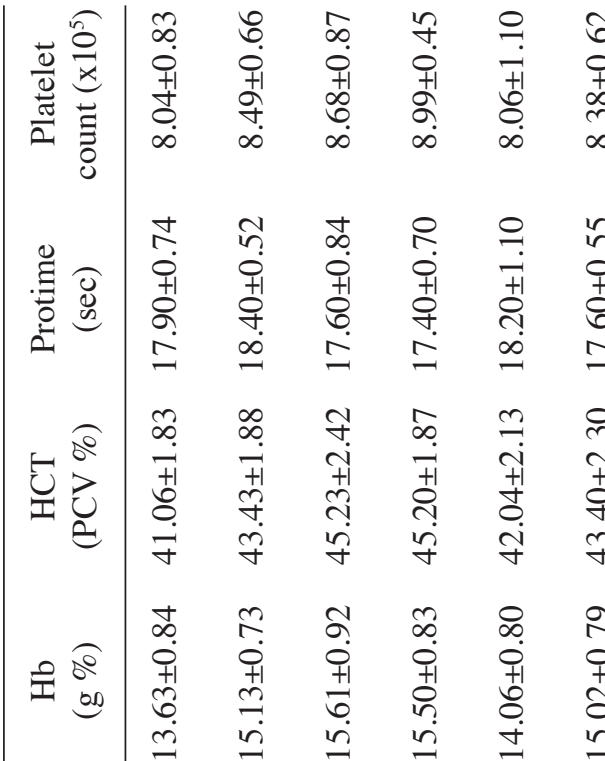

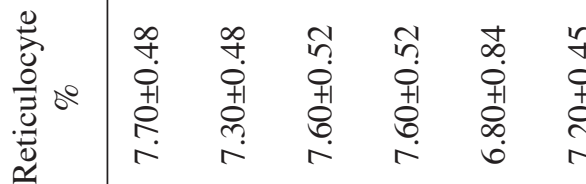

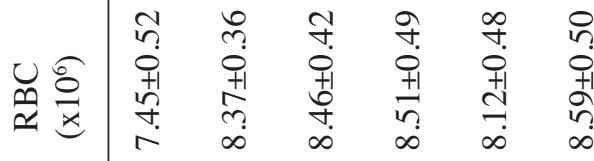

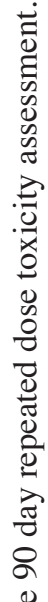

Ð

$\Xi$

$\stackrel{n}{\pi}$

$\frac{\text { U }}{\text { డี }}$

范

这

莺

ฮี

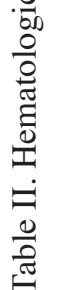

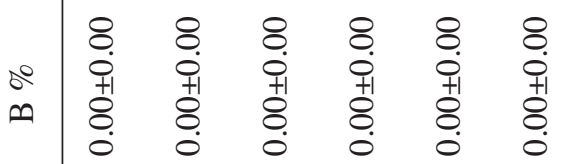

กิ ก ก ร ๆ ก ก

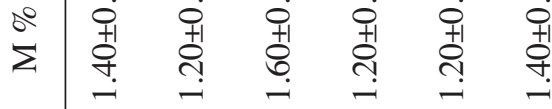

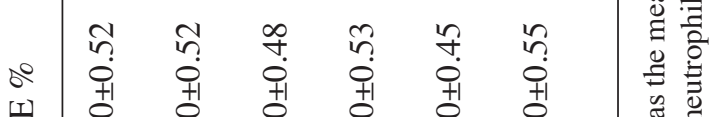

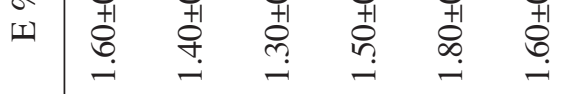

ने ले ते तु $₹$ मे

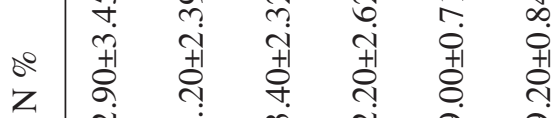

य ते ते बें ते

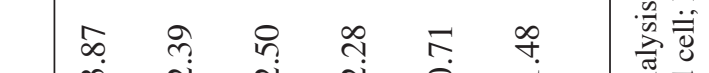

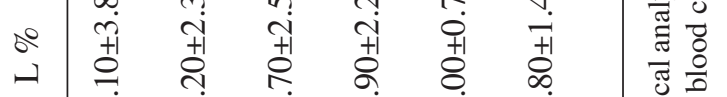

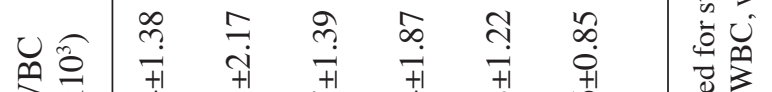

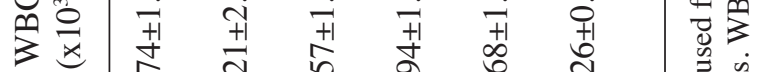

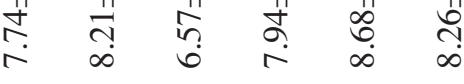

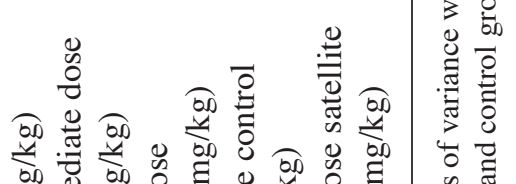

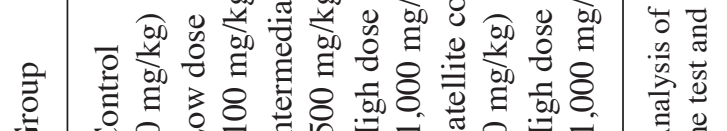

है

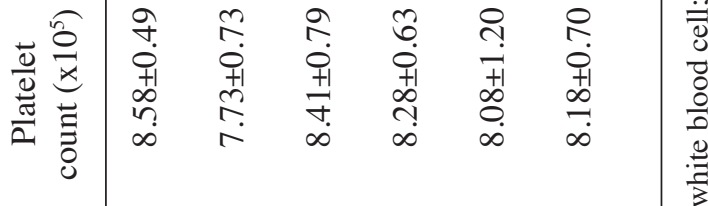

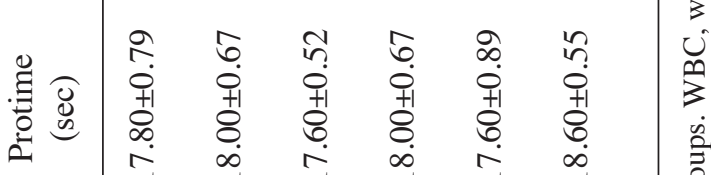

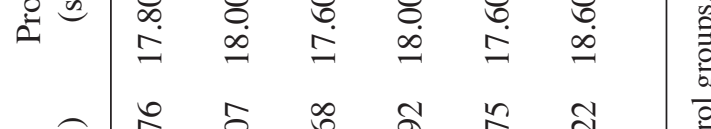

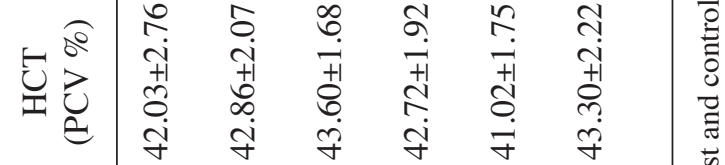

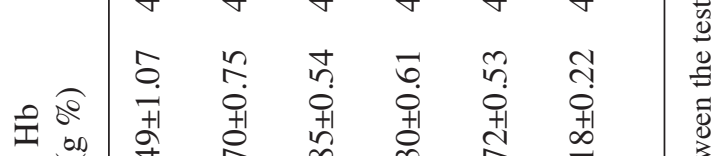

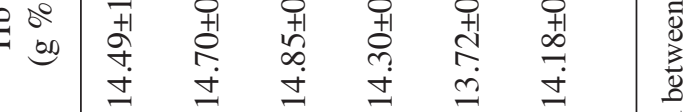

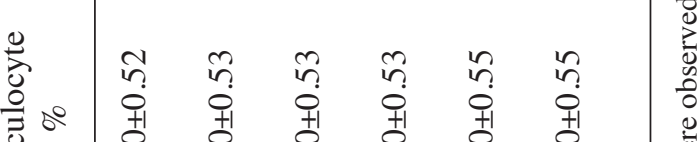

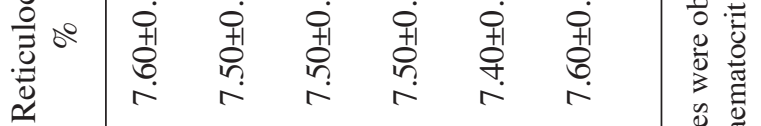

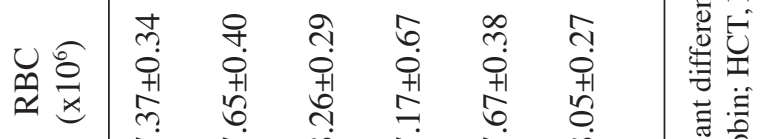

这

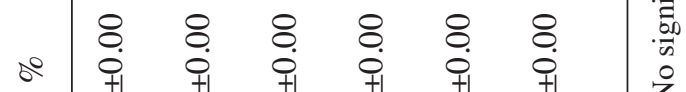

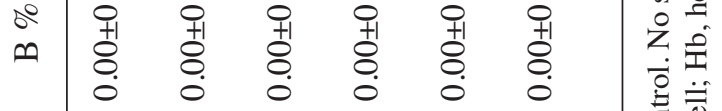

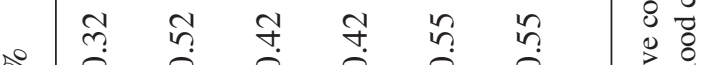

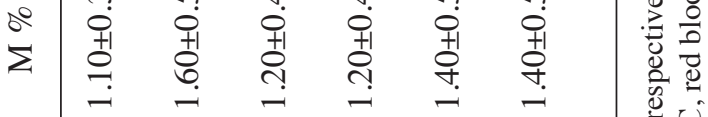

n $n$ ก

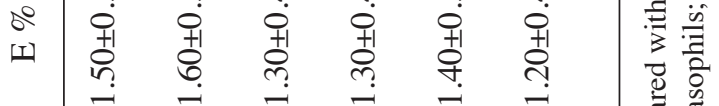

\&

范

节

崩

$\overbrace{}^{\overline{0}}$

这

藏

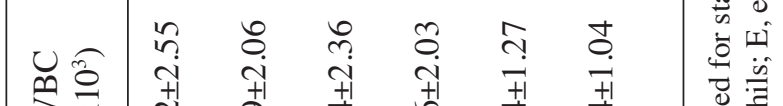

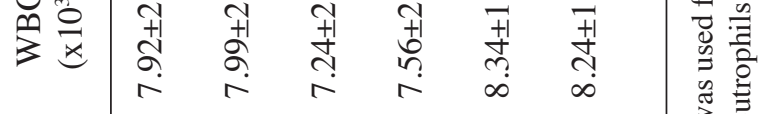

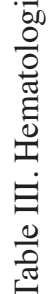

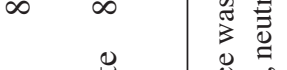

कि完产

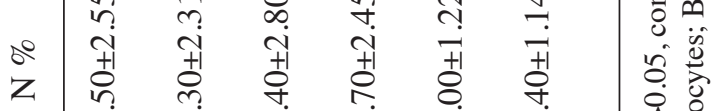

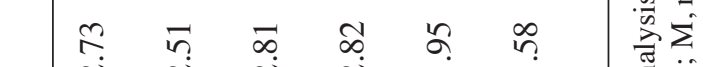

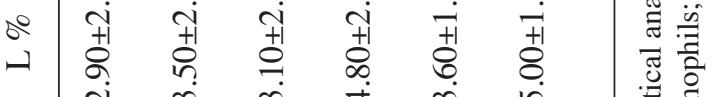

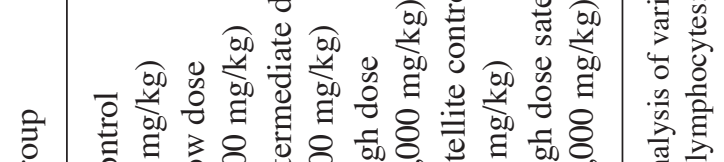

亏 


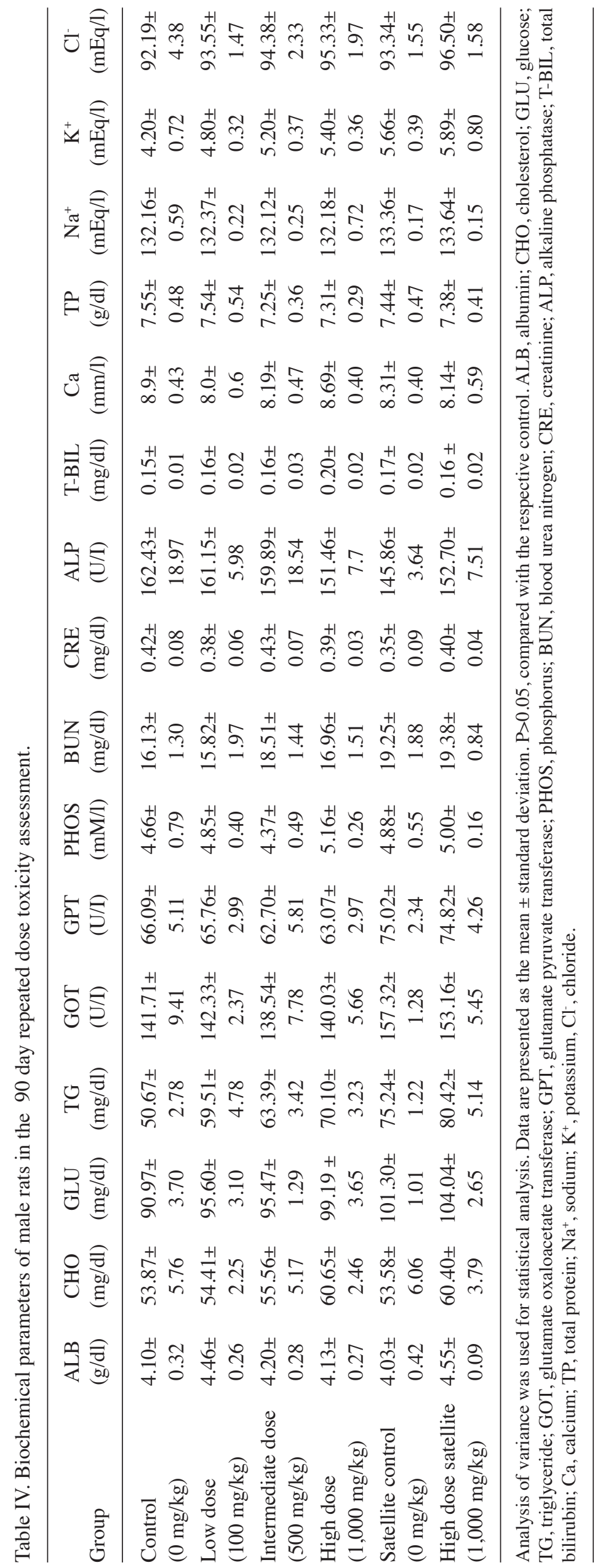




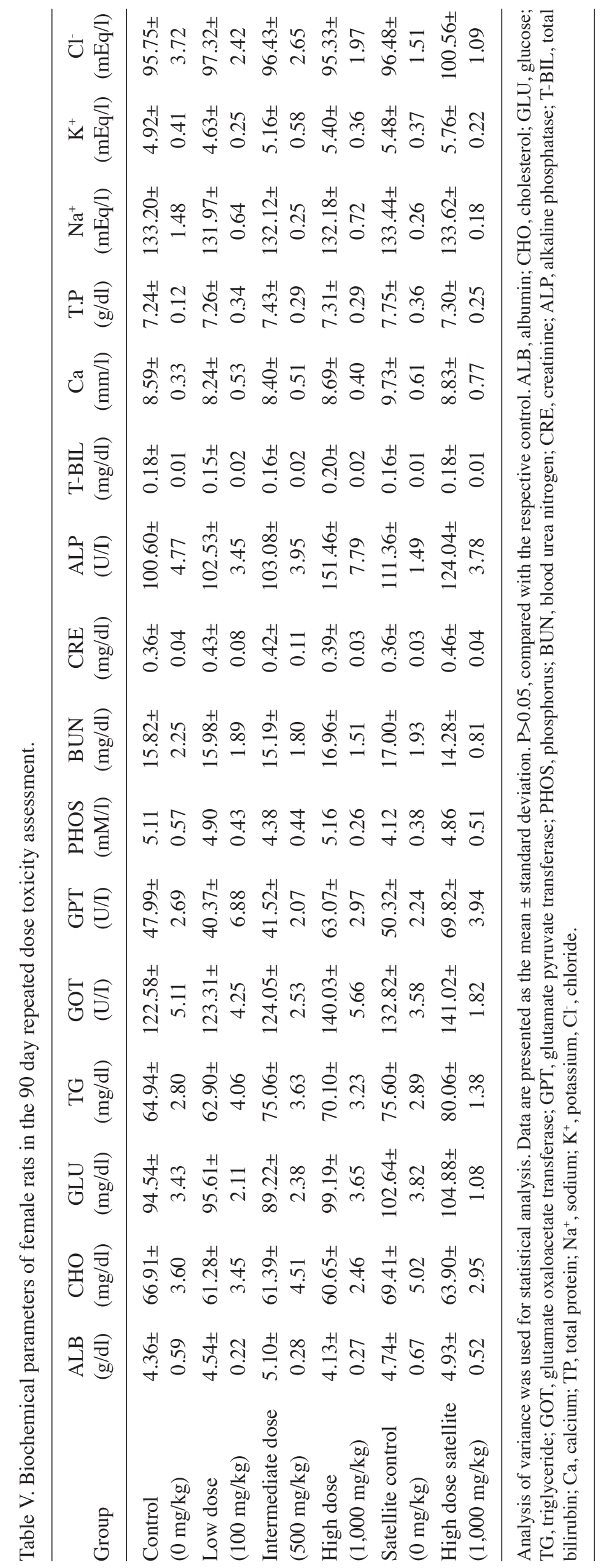


Table VI. Ames test of the number of colonies in the negative control, CEC and positive control groups.

\begin{tabular}{|c|c|c|c|c|c|c|}
\hline \multirow{3}{*}{$\begin{array}{l}\text { Salmonella } \\
\text { typhimurium strain }\end{array}$} & \multicolumn{6}{|c|}{ Colony count } \\
\hline & \multicolumn{2}{|c|}{ Negative control } & \multicolumn{2}{|c|}{$\operatorname{CEC}(5,000 \mu \mathrm{g} /$ plate $)$} & \multicolumn{2}{|c|}{ Positive control } \\
\hline & $+\mathrm{S}-9$ & $-S-9$ & $+\mathrm{S}-9$ & $-S-9$ & $+\mathrm{S}-9$ & $-S-9$ \\
\hline TA-98 & $10.33 \pm 1.52$ & $9.00 \pm 1.00$ & $16.33 \pm 0.57^{b}$ & $15.66 \pm 1.52^{\mathrm{b}}$ & $196.00 \pm 4.35^{\mathrm{a}}$ & $188.66 \pm 2.51^{\mathrm{a}}$ \\
\hline TA-100 & $15.00 \pm 1.00$ & $11.66 \pm 0.57$ & $12.00 \pm 1.00^{\mathrm{b}}$ & $12.66 \pm 1.52^{\mathrm{b}}$ & $207.33 \pm 3.05^{\mathrm{a}}$ & $196.33 \pm 6.43^{\mathrm{a}}$ \\
\hline TA-102 & $11.33 \pm 0.57$ & $10.66 \pm 1.15$ & $9.33 \pm 1.53^{\mathrm{b}}$ & $12.33 \pm 0.57^{\mathrm{b}}$ & $190.33 \pm 2.08^{\mathrm{a}}$ & $179.00 \pm 2.64^{\mathrm{a}}$ \\
\hline TA-1535 & $8.33 \pm 1.52$ & $10.66 \pm 1.52$ & $9.66 \pm 2.08^{b}$ & $11.00 \pm 1.00^{\mathrm{b}}$ & $198.66 \pm 2.51^{\mathrm{a}}$ & $188.33 \pm 4.51^{\mathrm{a}}$ \\
\hline TA-1537 & $9.66 \pm 2.08$ & $10.00 \pm 2.00$ & $11.00 \pm 2.00^{\mathrm{b}}$ & $11.66 \pm 1.15^{\mathrm{b}}$ & $192.33 \pm 1.52^{\mathrm{a}}$ & $183.33 \pm 5.03^{\mathrm{a}}$ \\
\hline
\end{tabular}

Analysis of variance and Dunnett's test were used for statistical analysis. Data are presented as the mean \pm standard deviation. ${ }^{a} \mathrm{P}<0.01$, vs. negative control; ${ }^{\mathrm{b}} \mathrm{P}>0.05$, vs, negative control. S-9, S-9 liver fraction (metabolic activation). CEC, curcuminoid-essential oil complex.

Table VII. Cytogenetic analysis with the mammalian bone marrow chromosome aberration test.

\begin{tabular}{|c|c|c|c|c|c|c|}
\hline Group & $\begin{array}{c}\text { Time of } \\
\text { sacrifice (h) }\end{array}$ & Gender & $\begin{array}{l}\text { Number of } \\
\text { animals }\end{array}$ & $\begin{array}{c}\text { Total } \\
\text { aberrations (n) }\end{array}$ & $\begin{array}{c}\text { Cells with } \\
\text { aberration (n) }\end{array}$ & $\begin{array}{c}\text { Mitotic } \\
\text { index }(\%)\end{array}$ \\
\hline \multirow[t]{4}{*}{ CEC $(2,000$ mg/kg) } & \multirow[t]{2}{*}{18} & M & 5 & $1.20 \pm 1.10$ & $1.00 \pm 1.00$ & $6.06 \pm 0.20$ \\
\hline & & $\mathrm{F}$ & 5 & $2.00 \pm 0.71$ & $1.40 \pm 0.55$ & $6.08 \pm 0.24$ \\
\hline & \multirow[t]{2}{*}{42} & M & 5 & $1.00 \pm 1.00$ & $0.60 \pm 0.55$ & $5.80 \pm 0.19$ \\
\hline & & $\mathrm{F}$ & 5 & $1.20 \pm 1.30$ & $0.80 \pm 0.84$ & $5.82 \pm 0.68$ \\
\hline \multirow{4}{*}{$\begin{array}{l}\text { Positive control } \\
\text { (cyclophosphamide) }\end{array}$} & \multirow[t]{2}{*}{18} & M & 5 & $240.60 \pm 5.32^{\mathrm{a}}$ & $52.80 \pm 6.46^{\mathrm{a}}$ & $1.90 \pm 0.27^{\mathrm{a}}$ \\
\hline & & $\mathrm{F}$ & 5 & $237.40 \pm 7.09^{\mathrm{a}}$ & $51.60 \pm 6.27^{\mathrm{a}}$ & $1.80 \pm 0.32^{\mathrm{a}}$ \\
\hline & \multirow[t]{2}{*}{42} & M & 5 & $216.00 \pm 9.27^{\mathrm{a}}$ & $48.00 \pm 7.58^{\mathrm{a}}$ & $1.98 \pm 0.36^{\mathrm{a}}$ \\
\hline & & $\mathrm{F}$ & 5 & $212.00 \pm 4.45^{\mathrm{a}}$ & $54.40 \pm 5.68^{\mathrm{a}}$ & $2.14 \pm 0.18^{\mathrm{a}}$ \\
\hline \multirow[t]{4}{*}{ Negative control } & \multirow[t]{2}{*}{18} & M & 5 & $2.20 \pm 0.84$ & $1.80 \pm 0.84$ & $6.38 \pm 0.28$ \\
\hline & & F & 5 & $2.40 \pm 0.55$ & $1.80 \pm 0.84$ & $6.06 \pm 0.21$ \\
\hline & \multirow[t]{2}{*}{42} & M & 5 & $2.00 \pm 0.71$ & $1.20 \pm 0.45$ & $6.82 \pm 0.40$ \\
\hline & & $\mathrm{F}$ & 5 & $1.40 \pm 0.89$ & $1.20 \pm 0.45$ & $5.78 \pm 0.49$ \\
\hline
\end{tabular}

Analysis of variance was used for statistical analysis. Data are presented as the mean \pm standard deviation. ${ }^{a} \mathrm{P}<0.01$, compared with the negative control. CEC, curcuminoid-essential oil complex; M, male; F, female.

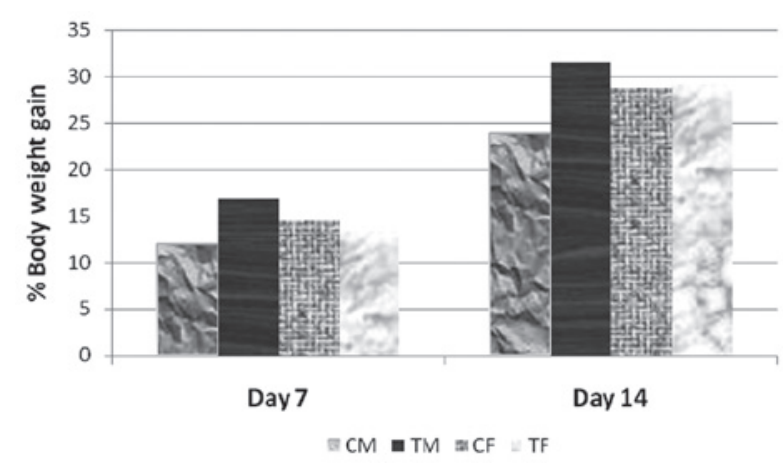

Figure 1. Percentage body weight gain of mice in the assessment of acute toxicity. (Student's $t$-test; $\mathrm{P}>0.05$, compared with the respective control. CM, control males; TM, test males; $\mathrm{CF}$, control females; TF, test females.

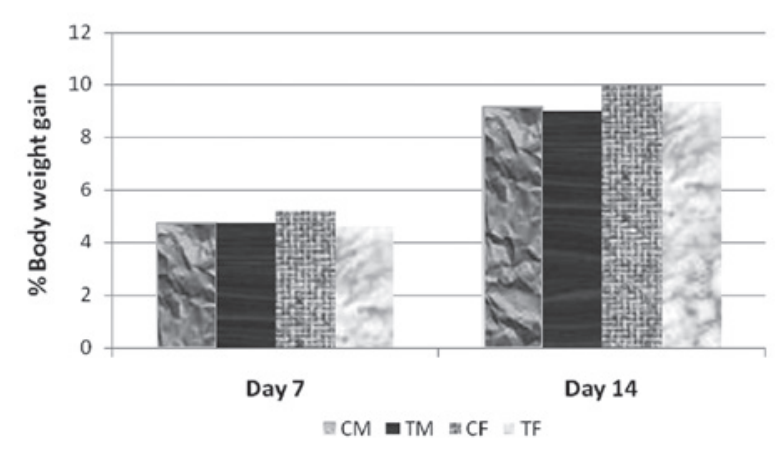

Figure 2. Percentage body weight gain of rats in the assessment of acute toxicity. (Student's $t$-test; $\mathrm{P}>0.05$, compared with the respective control. CM, control males; TM, test males; CF, control females; TF, test females.
Mammalian bone marrow chromosome aberration test. The mammalian bone marrow chromosome aberration test was performed in the present study to detect any structural chromo- somal aberrations induced by CEC in the bone marrow cells. Bone marrow metaphase preparations were made following formation of a hypotonic solution and fixation. Metaphase 


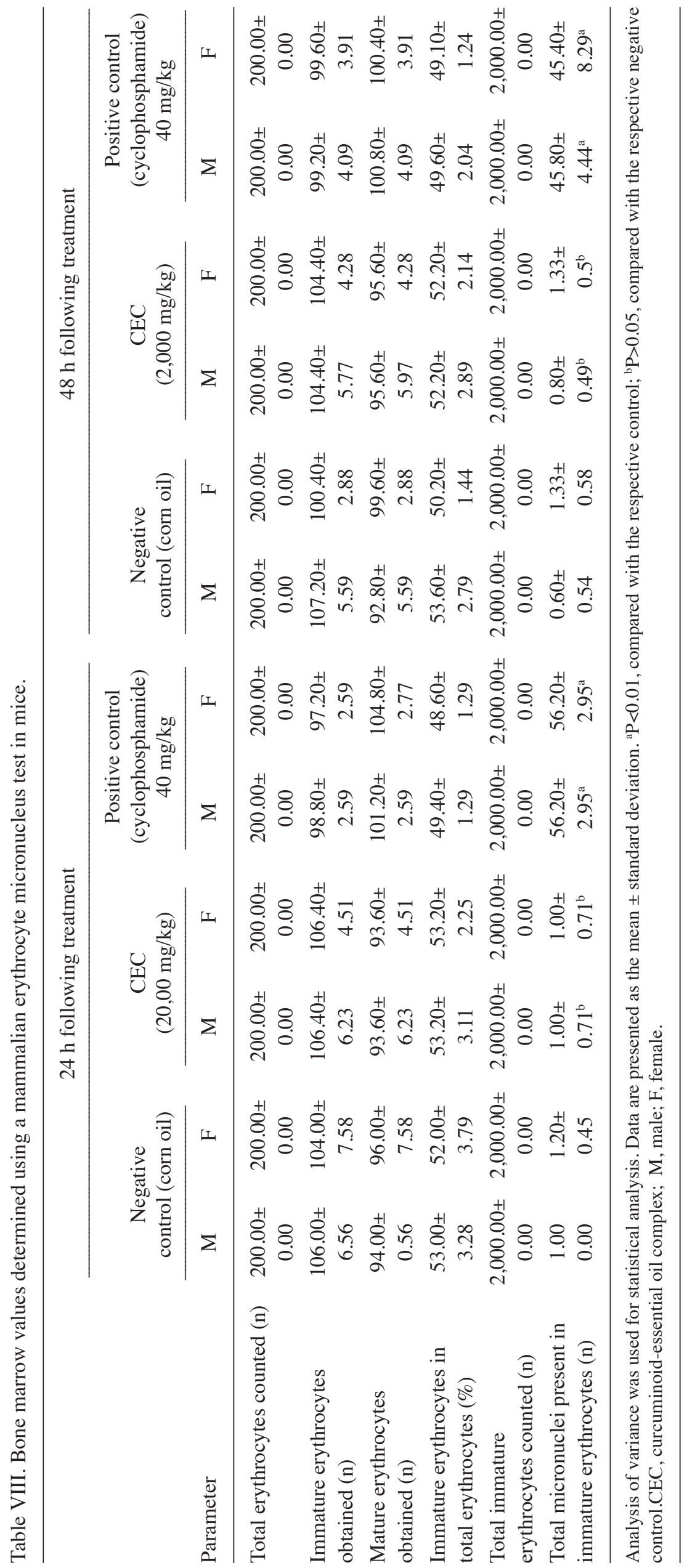




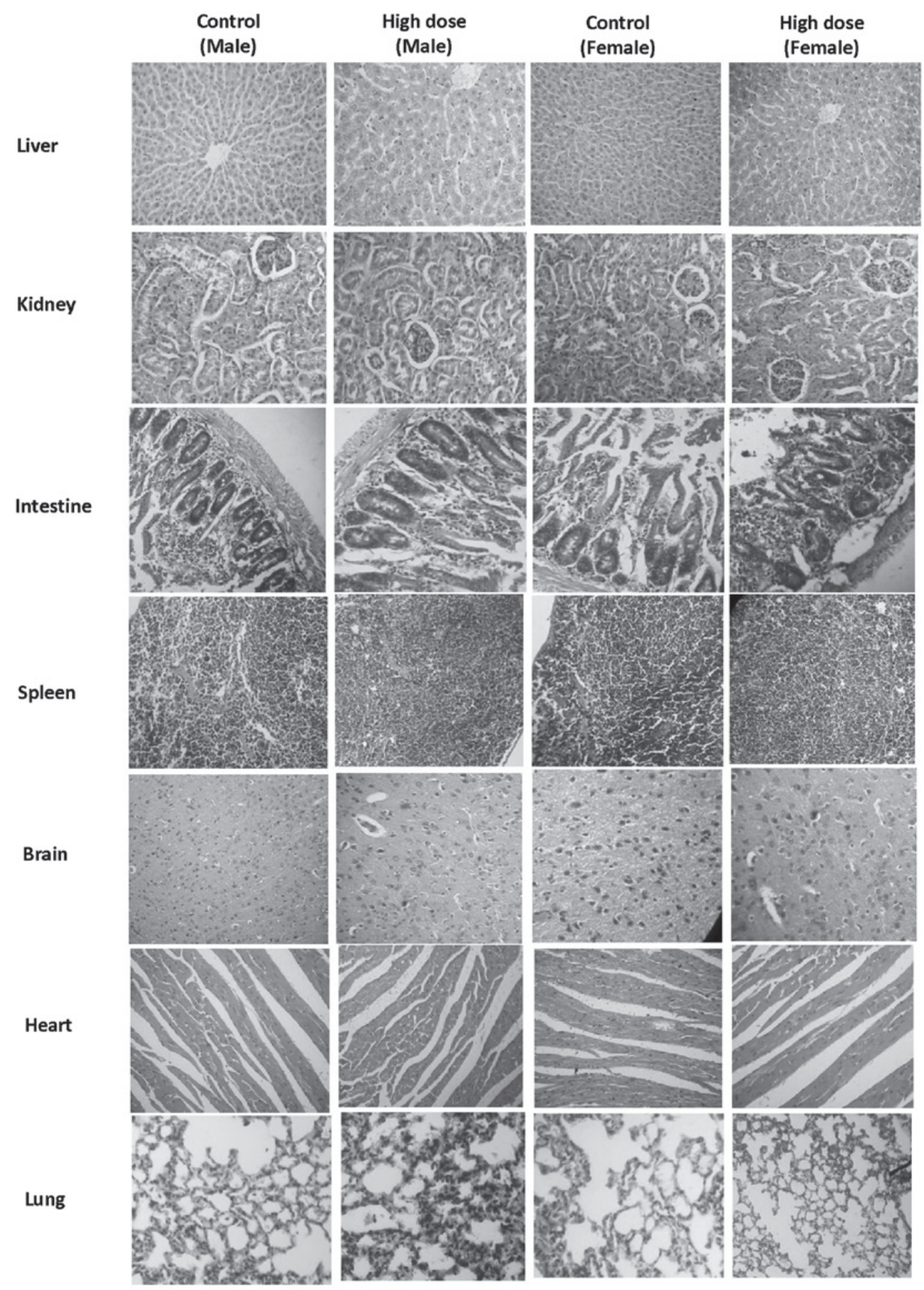

Figure 3. Histopathological sections of major organs in the 90 day repeated dose toxicity assessment. Hemorrhage, alveolar edema and perivascular cuffing were recorded in the lung tissues of the control and high dose group, as well as cysts and hydronephrosis in the kidney. Cellular swelling and lipid vacuolation was recorded in the liver of all groups and was considered to be within the normal range. There were no histopathological findings, which distinguished the CEC-treated animals from the controls. Magnification, x100.

preparations were stained with Giemsa, and aberrations were classified and scored. No evidence of numerical or structural aberrations were observed at the maximum tolerated dose of CEC at any time point of bone marrow harvest (Table VII). The total number of cells with aberration in the CEC group were not significantly different from the negative control group. In the positive control group, data was significantly different, compared with that of in negative control group. Therefore, $\mathrm{CEC}$ was confirmed as non-mutagenic at $2,000 \mathrm{mg} / \mathrm{kg}$ bw.

Mammalian erythrocyte micronucleus test in mice. The mammalian erythrocyte micronucleus test was performed in the present study to investigate the mutagenic effects of CEC in Swiss albino mice. Following the administration of 
drugs in the respective groups, the animals were monitored daily for signs and symptoms of toxicity or mortality prior to sacrifice. No mortality of signs and symptoms of toxicity were observed in any of the animals in the CEC groups. Following sacrifice of five males and five females from each group, at 24 and $48 \mathrm{~h}$ post-dose administration, the femora were removed and the bone marrow collected to produce smears, which were then stained and examined microscopically. No significant changes were observed in the numbers of immature and mature erythrocytes in the animals treated with $2,000 \mathrm{mg} / \mathrm{kg}$ bw CEC at 24 and $48 \mathrm{~h}$, compared with their respective negative control animals (Table VIII). Therefore, the percentage of immature erythrocytes in the treated animals at a dose of $2,000 \mathrm{mg} / \mathrm{kg}$ bw at 24 and $48 \mathrm{~h}$, were comparable with the negative control. However, the numbers of immature and mature erythrocytes were significantly higher in the positive control group (40 mg/kg wt) at 24 and $48 \mathrm{~h}$, compared with the negative control group.

No significant changes in the micronuclei were induced by CEC at either 24 or $48 \mathrm{~h}$, compared with their negative control counterparts. As no significant effect was seen in the CEC-treated animals, it was concluded that CEC exhibited no mutagenic potential.

\section{Discussion}

Curcumin has wide spectrum of therapeutic activity, however the major limitation with curcumin is its poor oral absorption and, thus low bioavailability. CEC is a curcumin formulation, exhibiting increased bioavailability (28), however, it is important to ensure that increased bioavailability does not increase toxicity, which was the focus of investigation in the present study.

In the assessment and evaluation of the toxic characteristics of a test substance, determination of acute oral toxicity in mice and rats is usually an initial step, and evaluation in two species (rats and mice) is advantageous to confirm the findings (30). The results of acute toxicity obtained in the present study indicated that CEC was safe up to $5,000 \mathrm{mg} / \mathrm{kg}$ in rats and mice. The LD50 for mice and rats was $>5,000 \mathrm{mg} /$ $\mathrm{kg}$, which confirms CEC as a nontoxic material. The 90 day repeated dose toxicity test in rats further confirmed the non-toxicity of CEC, as the repeated administration of CEC for 90 days in rats at a dose of $1,000 \mathrm{mg} / \mathrm{kg}$ bw caused no observable toxic effects, compared with the corresponding control group.

The Ames test is commonly used as an initial screen for genotoxic activity and, in particular, for point mutation activity (31). The results of the Ames test in the present study indicated that CEC was non-mutagenic up to 5,000 $\mu \mathrm{g} / \mathrm{plate}$, compared with the untreated control. Similarly, the results of the chromosomal aberration test indicated that CEC was non-mutagenic at a dose of $2,000 \mathrm{mg} / \mathrm{kg}$ bw in rats.

The mammalian micronucleus test is used for the detection of damage induced by a test substance towards the mitotic apparatus of erythroblasts, by analyzing erythrocytes sampled from bone marrow (32). In the present study, no effects were observed in the micronuclei at either 24 or $48 \mathrm{~h}$ following treatment with CEC, compared with their negative control counterparts. As no significant effect was seen in the treated animals, it was concluded that CEC did not exhibit any mutagenic potential.

In conclusion, the results of the present study indicated that CEC had no toxic effects in the animal models used, as per OECD guidelines. The results of the in vitro assessment also confirmed the non-toxicity and safety of CEC. Taken together, CEC was observed to be non-toxic and safe, and was supported by evidence from investigations of acute toxicity, repeated dose toxicity and mutagenicity.

\section{Acknowledgements}

The authors would like to thank the Spices Board, Ministry of Commerce and Industry, Government of India (Cochin, India) for financial support and Arjuna Natural Extracts Ltd. (Aluva, India) for providing the sample of CEC $\left(\right.$ BCM- $95^{\circledR} /$ Biocurcumin $\left.^{\mathrm{TM}}\right)$.

\section{References}

1. Ravindran PN, Nirmal Babu K, Sivaraman K. Turmeric. The golden spice of life. In: Turmeric. The Genus Curcuma. Boca Raton, FL, USA: CRC Press; 2007. p. 1-14.

2. Maheshwari RK, Singh AK, Gaddipati J and Srimal RC: Multiple biological effects of curcumin: A short review. Life Sci 78: 2081-2087, 2006

3. Chandra D and Gupta SS: Anti-inflammatory and anti-arthritic activity of volatile oil of Curcuma longa (Haldi). Indian J Med Res 60: 138-142, 1972.

4. Aggarwal BB, Sundaram C, Malani N and Ichikawa H: Curcumin: The Indian solid gold. Adv Exp Med Biol 595: 1-75, 2007.

5. Aggarwal BB and Shishodia S: Molecular targets of dietary agents for prevention and therapy of cancer. Biochem Pharmacol 71: 1397-1421, 2006.

6. Sharma RA, Gescher AJ and Steward WP: Curcumin: The story so far. Eur J Cancer 41: 1955-1968, 2005.

7. Duvoix A, Blasius R, Delhalle S, Schnekenburger M, Morceau F Henry E, Dicato M and Diederich M: Chemopreventive and therapeutic effects of curcumin. Cancer Lett 223: 181-190, 2005.

8. Joe B, Vijayakumar M and Lokesh BR: Biological properties of curcumin-cellular and molecular mechanisms of action. Crit Rev Food Sci Nutr 44: 97-111, 2004.

9. Menon LG, Kuttan R and Kuttan G: Inhibition of lung metastasis in mice induced by B16F10 melanoma cells by polyphenolic compounds. Cancer Lett 95: 221-225, 1995.

10. Menon LG, Kuttan R and Kuttan G: Anti-metastatic activity of curcumin and catechin. Cancer Lett 141: 159-165, 1999.

11. Chen HW, Yu SL, Chen JJ, Li HN, Lin YC, Yao PL, Chou HY, Chien CT, Chen WJ, Lee YT and Yang PC: Anti-invasive gene expression profile of curcumin in lung adenocarcinoma based on a high throughput microarray analysis. Mol Pharmacol 65: 99-110, 2004

12. Tønnesen HH, Másson M and Loftsson T: Studies of curcumin and curcuminoids. XXVII. Cyclodextrin complexation: Solubility, chemical and photochemical stability. Int J Pharm 244: 127-135, 2002.

13. Pan MH, Huang TM and Lin JK: Biotransformation of curcumin through reduction and glucuronidation in mice. Drug Metab Dispos 27: 486-494, 1999.

14. Johnson JJ and Mukhtar H: Curcumin for chemoprevention of colon cancer. Cancer Lett 255: 170-181, 2007.

15. Sharma RA, Euden SA, Platton SL, Cooke DN, Shafayat A, Hewitt HR, Marczylo TH, Morgan B, Hemingway D, Plummer SM, et al: Phase I clinical trial of oral curcumin: Biomarkers of systemic activity and compliance. Clin Cancer Res 10: 6847-6854, 2004.

16. Anand P, Kunnumakkara AB, Newman RA and Aggarwal BB: Bioavailability of curcumin: Problems and promises. Mol Pharm 4: 807-818, 2007. 
17. Cui J, Yu B, Zhao Y, Zhu W, Li H, Lou H and Zhai G: Enhancement of oral absorption of curcumin by self-microemulsifying drug delivery systems. Int J Pharm 371: 148-155, 2009.

18. Marczylo TH, Verschoyle RD, Cooke DN, Morazzoni P, Steward WP and Gescher AJ: Comparison of systemic availability of curcumin with that of curcumin formulated with phosphatidylcholine. Cancer Chemother Pharmacol 60: 171-177, 2007.

19. Ganiger S, Malleshappa HN, Krishnappa H, Rajashekhar G Ramakrishna Rao V and Sullivan F: A two generation reproductive toxicity study with curcumin, turmeric yellow, in Wistar rats. Food Chem Toxicol 45: 64-69, 2007.

20. Shankar TN, Shantha NV, Ramesh HP, Murthy IA and Murthy VS: Toxicity studies on turmeric (Curcuma longa) Acute toxicity studies in rats, guineapigs and monkeys. Indian J Exp Biol 18: 73-75, 1980.

21. Ravindranath V and Chandrasekhara N: Absorption and tissue distribution of curcumin in rats. Toxicology 16: 259-265, 1980.

22. Wahlström B and Blennow G: A study on the fate of curcumin in the rat. Acta Pharmacol Toxicol (Copenh) 43: 86-92, 1978.

23. Burgos-Morón E, Calderón-Montaño JM, Salvador J, Robles A and López-Lázaro M: The dark side of curcumin. Int J Cancer 126: 1771-1775, 2010.
24. Kizhakkedath R: Clinical evaluation of a formulation containing Curcuma longa and Boswellia serrata extracts in the management of knee osteoarthritis. Mol Med Rep 8: 1542-1548, 2013.

25. EFSA Panel on Food Additives and Nutrient Sources added to Food (ANS); Scientific Opinion on the reevaluation of curcumin (E 100) as a food additive. EFSA Journal 8: 1679, 2010

26. Joint FAO/WHO Expert Committee on Food Additives (JECFA): Summary and conclusions of the sixty-first meeting. JECF, Rome, Italy, pp1-22, 2010.

27. Henrotin Y, Priem F and Mobasheri A: Curcumin: a new paradigm and therapeutic opportunity for the treatment of osteoarthritis: curcumin for osteoarthritis management. Springerplus. doi: 10.1186/2193-1801-2-56.

28. Antony B, Merina B, Iyer VS, Judy N, Lennertz K and Joyal S: A pilot cross-over study to evaluate human oral bioavailability of BCM-95CG (Biocurcumax), a novel bioenhanced preparation of Curcumin. Indian J Pharm Sci 70: 445-449, 2008.

29. OECD Guidelines for Testing of Chemicals: Acute oral toxicity - fixed dose procedure, test no. 420. Organisation for Economic Co-operation and Development. Paris, France, pp1-14, 2002.

30. Parasuraman S: Toxicological screening. J Pharmacol Pharmacother 2: 74-79, 2011.

31. Maron DM and Ames BN: Revised methods for the Salmonella mutagenicity test. Mutat Res 113: 173-215, 1983.

32. Schmid W: The micronucleus test. Mutat Res 31: 9-15, 1975. 